\title{
Molecular mechanism of hepatocellular carcinoma
}

\author{
Seung Kew Yoon \\ Division of Hepato-Gastroenterology, Department of Internal Medicine, College of Medicine, The Catholic University of Korea; The \\ Catholic University Liver Research Center \& WHO Collaborating Center of Viral Hepatitis, Seoul, South Korea.
}

Correspondence to: Prof. Seung Kew Yoon, Division of Hepato-Gastroenterology, Department of Internal Medicine, College of Medicine, The Catholic University of Korea, \#222, Banpo-daero, Seocho-gu, Seoul 137-701, South Korea. E-mail: yoonsk@catholic.ac.kr

How to cite this article: Yoon SK. Molecular mechanism of hepatocellular carcinoma. Hepatoma Res 2018;4:42.

http://dx.doi.org/10.20517/2394-5079.2018.23

Received: 19 Mar 2018 First Decision: 19 Apr 2018 Revised: 12 Jul 2018 Accepted: 17 Jul 2018 Published: 8 Aug 2018

Science Editor: Guang-Wen Cao Copy Editor: Jun-Yao Li Production Editor: Huan-Liang Wu

\begin{abstract}
Development of hepatocellular carcinoma (HCC) is very complex and occurs through a multistep biological process of malignant transformation of normal hepatocytes in which various factors, including genetic and epigenetic alterations, regulation of oxidative stress, inflammation, and immunity are involved. To date, numerous studies have described the molecular pathogenesis of HCC, but the precise molecular mechanisms of HCC development remain unclear. Emerging single-cell transcriptome analysis technology is a powerful tool for defining sub-populations within heterogeneous bulk tumor tissue and allows molecular characterization of each cell. This breakthrough method can unveil the molecular mechanisms of HCC. In this article, I discuss recent advances in the molecular pathogenesis of HCC through this newly emerging concept of single-cell analysis.
\end{abstract}

Keywords: Hepatocellular carcinoma, molecular mechanism, pathogenesis, characterization

\section{INTRODUCTION}

Hepatocellular carcinoma (HCC) is the fifth most prevalent cancer in men, the seventh most common in women and the third leading cause of cancer-related deaths worldwide ${ }^{[1,2]}$. HCC accounts for approximately $85 \%$ of liver cancers ${ }^{[1]}$ and is characterized by a highly heterogenetic pathogenesis with an aggressive clinical course leading to poor survival. The risk factors for HCC are relatively well defined compared with those for other cancers. The risk factors include chronic hepatitis B virus (HBV), hepatitis C virus (HCV) infection, chronically heavy alcohol consumption, aflatoxin B1 (AFB1) exposure and nonalcoholic fatty liver disease (NAFLD $^{[2]}$. The incidence of HCC is considered to be significantly higher in eastern Asia and sub-Saharan Africa, which are endemic areas of HBV infection, but the incidence of HCC is rising in Western countries due to increases in HCV infection, chronic alcoholic intake and NAFLD ${ }^{[3,4]}$.

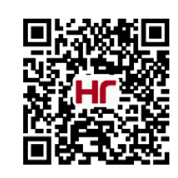


In an era of precision medicine for cancer treatment, it is essential to investigate the molecular mechanisms of carcinogenesis and tumor progression. In addition to array-based comparative analyses, genome-wide association studies (GWAS), next-generation sequencing (NGS), and RNA sequencing analyses for cancer research, studies on host immune mechanisms associated with immune evasion of cancer are also required to develop tumor immunotherapy.

It is generally accepted that hepatocarcinogenesis is very complex and occurs through a multistep biological process during malignant transformation of normal hepatocytes in which various factors, including genetic and epigenetic alterations, are involved. Specifically, recent advances in NGS technologies have facilitated a more profound understanding of the molecular mechanisms of HCC, which have contributed to the development of targeted therapies for cancers by identifying genes and associated signaling involved in carcinogenesis and tumor progression. Despite these advances, it remains difficult to effectively treat advanced HCC because most advanced cases are accompanied by poor liver function and liver cirrhosis. Surgical approaches, including resection and liver transplantation, are not available in these cases, so molecular targeted therapy combined with immunotherapy has become an alternative strategy to prolong patients' survival. To this end, further investigation of the molecular pathways involved in hepatocarcinogenesis and tumor progression is indispensable.

In this article, I discuss recent advances in molecular pathogenesis based on major etiologicfactors for the development of HCC.

\section{MOLECULAR MECHANISMS OF HBV-RELATED HCC}

Among the major risk factors for HCC, HBV is the most common causative agent that increases the incidence of HCC in East Asia and sub-Saharan Africa. The HBV genome contains four genes (C, S, X and P), which encode the core protein, envelope protein, X protein and a polymerase. Among them, hepatitis B X protein $(\mathrm{HBx})$ is known to have a critical role in the development of HCC. Accumulating evidence reveals that HBx has multifunctional activities including interruption of apoptosis in hepatocytes ${ }^{[5]}$ and DNA repair mechanisms through transcriptional regulations of $\mathrm{p}^{\left[{ }^{[6]}\right.}$, facilitation of cellular signal transduction, cell cycle progression, and maintenance of genetic stability of HBx through interactions with different host factors $^{[7]}$.

Chronic HBV infection enables viral DNA to integrate into the host genome, leading to an oncogenic transformation. A recent NGS study revealed that HBV integration was found in more than $80 \%$ of HBV positive HCC and was more extensive in tumor tissue compared with surrounding non-tumor tissue ${ }^{[8]}$. In particular, three cancer-associated genes, telomerase reverse transcriptase (TERT), mixed-lineage leukemia 4 (MLL4) and cyclin E1 (CCNE1) were observed at frequent integration sites in HBV positive tumors. These findings suggest a significant association between HBV integration and hepatocarcinogenesis. Moreover, mutations in TERT promoter are found in more than $50 \%$ of HCC tissue ${ }^{[9]}$. Although the mechanism by which TERT is activated in cancer is not clearly understood, and a recent study revealed that the GA-binding protein transcription factor (GABP), a member of the E-twenty six (ETS) transcription factor family, is selectively recruited to the mutated TERT promoter and activates TERT expression ${ }^{[10]}$.

Accumulating evidence has shown that HBx plays important roles in hepatocarcinogenesis. Several mechanisms by which HBx may function at the molecular and cellular levels are as follows: (1) transactivation of promoters of cAMP response element binding protein (CREB) response element (CRE)-containing genes, including the oncogene Yes-associated protein $(\mathrm{YAP})^{[11]}$; (2) alteration of the DNA specificity of CREB and activating transcription factor 2 (ATF-2), resulting in binding and activation of the HBV enhancer ${ }^{[12]}$; (3) modulation of the DNA binding specificity of the p53 tumor suppressor, resulting in altered expression of 
its target genes ${ }^{[13]}$; and (4) regulation of cellular signaling pathways, such as activation of the Ras-Raf-MAPK pathway, Src-dependent pathway, PI3K-Akt pathway, inflammation-associated NF-kB/STAT-3 pathways, and wnt/ $\beta$-catenin pathway ${ }^{[14-18]}$. In addition, $\mathrm{HBx}$ affects epigenetic alterations through hyper- or hypomethylation of oncogenes and tumor suppressor genes, promoting histone acetylation and de-acetylation of tumor related genes as well as alterations of several microRNAs ${ }^{[19-21]}$.

\section{MOLECULAR MECHANISMS OF HCV-RELATED HCC}

$\mathrm{HCV}$ is a single stranded RNA virus with a 9.6-kb genome that encodes a large polyprotein that is cleaved at multiple sites to produce at least 10 proteins, including structural proteins [core, envelope (E)1 and E2] and non-structural (NS) proteins (proteins p7, NS2, NS3, NS4A, NS4B, NS5A and NS5B). Epidemiologic studies worldwide have provided evidence that $\mathrm{HCV}$ is the major risk factor of $\mathrm{HCC}$, and that chronic $\mathrm{HCV}$ infection induces liver fibrosis and cirrhosis, ultimately resulting in HCC. Historically, after identification of $\mathrm{HCV}$, it has been very difficult to study its pathogenesis and development into chronic liver diseases and HCC due to the lack of in vitro culture systems. To overcome this limitation, transgenic animal models expressing single or multiple HCV viral proteins were developed ${ }^{[22]}$. Despite these models, evidence for HCV playing a direct role in hepatocarcinogenesis remains controversial ${ }^{[23]}$. Because of revolutionary studies on viral replication in cell culture ${ }^{[24,25]}$, studies investigating hepatocarcinogenesis by HCV have been actively performed. HCV that replicates only in the cytoplasm of a hepatocyte has not yet integrated into the host genome. Integration of viral elements into the host genome leads to direct oncogenic transformation of hepatocytes. Several studies have provided evidence for a direct role of HCV in the pathogenesis of HCC. Previous studies have described the role of the HCV core protein related to the development of HCC. The HCV core protein activates STAT3 via an IL-6 autocrine pathway ${ }^{[26]}$ and enhances telomerases activity ${ }^{[27]}$, which can induce oncogenic transformational changes in hepatocytes. In addition, NS3/4A enhances cellular proliferation by activating phosphorylation of extracellular signal-regulated kinases (ERKs) and inhibiting p53-mediated apoptosis and p21 promoter activity ${ }^{[28,29]}$. In addition, chronic HCV infection induces oncogenic transformation in several ways: vigorous and continuous inflammation via $\mathrm{NF}-\mathrm{kB}^{[30]}$; oxidative stress, inducing DNA mutagenesis ${ }^{[31]}$; alteration of tumor suppressor genes ${ }^{[32]}$; direct alteration of the $\mathrm{wnt} / \beta$-catenin pathway by NS5A; and blocking of TGF- $\beta$ signaling through an interaction between TGF- $\beta$ receptor I (T $\beta$ R-I) and $\mathrm{NS}_{5} \mathrm{~A}^{[33]}$. Moreover, a recent study demonstrated that a lack of microRNA-122 resulted in a high incidence of tumors in a mouse model, but the mechanism by which this occurs has not been elucidated ${ }^{[34]}$.

Patients coinfected with HBV and hepatitis delta virus (HDV) have been reported to have rapid and serious disease progression ${ }^{[35]}$. However, little is known about whether and how co-infection of HBV and HDV can accelerate hepatocarcinogenesis. Recent studies suggest that marked liver inflammation, dysregulation of nuclear signaling pathways, increased oxidative stress, and epigenetic changes through HDV replication can enhance malignant transformation of hepatocytes, resulting in accelerated HCC development ${ }^{[36]}$.

\section{MOLECULAR MECHANISMS OF ALCOHOL-RELATED HCC}

Alcohol consumption, particularly over-consumption, is a serious global health problem. In general, heavy alcohol consumption leads to fatty liver, alcoholic steatohepatitis (ASH), cirrhosis, and eventually, HCC. ASH has been reported to progress to HCC at a rate of $3 \%-10 \%$ annually ${ }^{[37]}$. Though the pathogenetic mechanisms underlying alcohol-induced tumor initiation have been well defined, the alcohol-related signaling pathways involved in tumor promotion and progression are poorly understood.

Induction of Cytochrome p450 2E1 (CYP2E1), a member of the cytochrome p450 mixed-function oxidase system, by chronic alcohol consumption induces various biologic effects, such as increases in alcohol metabolism, enhanced oxidative stress, increased hepatotoxicity and interactions with various drugs, xenobiotics and carcinogen ${ }^{[38]}$. In particular, acetaldehyde produced by alcohol metabolism strongly induces oxidative 
stress, exacerbating liver diseases.

Recent studies have described the association between CYP2E1 polymorphisms and alcohol-related disorders, including alcoholic cirrhosis ${ }^{[39,40]}$, but no significant association was found between CYP2E1 Pst I/Rsa I polymorphism and HCC in a recent meta-analysis ${ }^{[41]}$. The molecular mechanisms for the direct role of alcohol on hepatocarcinogenesis remain unclear. However, a recent large-scale study using exome sequencing analysis of 243 liver tumors identified mutational signatures associated with specific risk factors and demonstrated that the Catenin beta 1 (CTNNB1) cluster was significantly related to alcohol as a risk factor for $\mathrm{HCC}^{[42]}$.

Sirtuins (SIRT1), nicotinamide adenine dinucleotide+ (NAD+)-dependent class III histone deacetylases, are linked to histone deacetylation and suppression of gene transcription, as well as the aging process ${ }^{[43]}$. A previous study illustrated that alcohol reduced hepatic SIRT1 expression, suggesting that loss of SIRT1 activity may initiate alcoholic liver disease ${ }^{[44]}$. However, the role of SIRT1 in the development and progression of tumors remains controversial. Numerous studies have demonstrated that SIRT1 acts to inhibit cell transformation and tumor progression, but other studies have suggested tumor promoting roles for SIRT $1^{[45-47]}$. In the context of HCC, a recent study by Jang et al. ${ }^{[48]}$ demonstrated the existence of positive feedback regulation between c-myc and SIRT1 that promotes tumor cell proliferation and predicts poor survival in human HCC. More recently, Mercer et al. ${ }^{[49]}$ performed in vivo experiments using ethanol feeding for long periods following injection of diethylnitrosamine (DEN). Their results suggest that chronic ethanol consumption activates Wnt/ $\beta$-catenin signaling, leading to increased hepatocyte proliferation and promotion of tumorigenesis following an initiating insult to the liver.

\section{MOLECULAR MECHANISM OF NASH-RELATED HCC}

NAFLD comprises a spectrum of liver disorders from simple fatty liver to NASH, hepatic fibrosis/cirrhosis and HCC. Individuals with NASH progress to HCC at a rate of $0.5 \%$ annually ${ }^{[50]}$. The risk factors for NAFLD include metabolic syndrome, visceral adiposity, extreme dieting and type 2 diabetes. Additional factors accelerating the transition from simple fatty liver (SFL) towards NASH and HCC include the gut microbiota, adipose-related inflammation, and excessive intake of lipids ${ }^{[51]}$. NASH associated with end-stage liver disease (ESLD) and HCC have become the second leading causes of liver transplantation in the USA ${ }^{[52]}$. Generally, SFL is reversible through weight control by exercise and calorie restriction. However, once SFL has progressed to NASH, medical attention is required because of its progression to ESLD or HCC. To date, numerous animal models have been established to investigate NASH-associated HCC, but these models have limitations for elucidating cause-and-effect relationships in the development of HCC. Nonetheless, these animal models have provided crucial evidence for pathogenic mechanisms in NASH-associated HCC. The process of liver injury occurs through activation of oxidative stress, endoplasmic reticulum (ER) stress, mitochondrial dysfunction, autophagy and intrahepatic NKT and CD8+ T cells ${ }^{[53]}$. During the inflammatory process in NASH, several cytokines, adipokines and lymphokines contribute to hepatic fibrogenesis via the regenerative process of hepatocytes ${ }^{[54]}$. In addition, recent studies have demonstrated that up-regulation of the insulin-like growth factor 1 (IGF1)/insulin substrate 1 pathway by hyperinsulinemia ${ }^{[55]}$ and enhancement of IL-6 and TNF levels by obesity ${ }^{[56]}$ contribute to hepatocarcinogenesis. Interestingly, a study by Yoshimoto et al. ${ }^{[57]}$ suggested that obesity-induced gut microbial metabolites promote liver cancer through the senescence secretome. In summary, the hepatic microenvironment of $\mathrm{NASH}$, which is considered to be a proinflammatory milieu, plays an important role in the development and progression of HCC.

Genetic factors as well as environmental factors have also been considered to be risk factors for NAFLDassociated HCC. The nucleotide polymorphisms rs738409 C/G, which results in an isoleucine to methionine substitution at residue 148 (I148M) in human patatinlike phospholipase domain containing 3, leads to an alteration of TAG remodeling in lipid droplets. This variant has been linked to an increased risk for liver 
fibrosis and NAFLD-related HCC ${ }^{[58]}$. Additionally, transmembrane 6 superfamily 2 (TM6SF2) E167K and glucokinase regulator (GCKR) rs780094 gene variants have been reported to be associated with a higher risk for fatty liver and liver fibrosis ${ }^{[59]}$. Although numerous factors that contribute to HCC from NAFLD have been revealed, there remain several unsolved issues for the molecular mechanism of HCC in the context of NAFLD, including the direct role of the gut microbiome, epigenetic regulation, identification of metabolomics profiles, and function of cancer stem cells linked to lipid metabolism.

\section{MOLECULAR MECHANISMS OF HCC BY SINGLE-CELL TRANSCRIPTOMIC ANALYSIS}

Recent advances in NGS technologies have facilitated deeper insights into the molecular mechanisms of tumor development and progression, thereby opening the way for a new era of personalized medicine. In particular, NGS-based transcriptome analysis (RNA-seq) has become a powerful tool for both characterizing the transcriptomes of each cell and profiling alternative splicing variants associated with cell function ${ }^{[60]}$. To date, almost all genomic studies have been carried out using bulk samples. However, RNA-seq using bulk tissue samples comprising various cell populations is inappropriate for comprehensively investigating transcriptomic profiling because each cell in the tumor is constantly differentiating, proliferating, and heterogeneous. Thus, the newly developed single-cell RNA sequencing (scRNA-seq) technology is a powerful approach to dynamically analyze the genetic and cytologic heterogeneity of each cell in specific tumor tissue, providing a more comprehensive understanding of the molecular mechanism of carcinogenesis and the process of cancer evolution. The heterogeneity of single cells is diversely manifested in morphologic and phenotypic characteristics, genomics, and proteomics. Proper targets that can be used to analyze the heterogeneity of cancer cell using scRNA-seq include cancer stem cells (CSCs), circulating tumor DNA (ctDNA) and cellfree DNA (cfDNA) ${ }^{[61-63]}$.

Recently, RNA-seq-based transcriptome analyses using tumor and non-tumor tissue from 10 HBV-related HCCs were first reported by Huang et al. ${ }^{[64]}$. Differentially expressed genes (DEGs; 1378) and differentially expressed exons (DEEs; 24,338) were identified in their study. Comprehensive functional analyses demonstrated that DEGs were most significantly enriched in cell growth-related, metabolism-related and immunerelated pathways, suggesting a very complicated mechanism for hepatocarcinogenesis. Furthermore, RNAseq data analyses at the exon level revealed a highly complex landscape of transcript-specific differential expression in HCC. In particular, a novel, highly up-regulated exon-exon junction was detected in the ATAD2 gene. This is the first study dealing with transcriptome profiles, including exon level expression changes and novel splicing variants using RNA-seq, and represents the most comprehensive characterization of HBV-related HCC transcriptomes as well as provides important clues for understanding the molecular mechanisms of HCC pathogenesis at system-wide levels. More recently, to further explore the dynamic mechanisms that simultaneously occur in genetic and epigenetic regulation on gene expression associated with heterogeneity at the single cell level in cancer, single-cell triple omics sequencing (scTrio-seq) techniques, including the genome, epigenome and transcriptome, have been developed ${ }^{[65]}$. Recently, Hou et al..$^{[66]}$ using scTrio-seq technology, have demonstrated correlations between genomic (copy-number variations, CNVs), transcriptomic, and methylomic data analyzed in the same individual cells in HCC. In addition, they revealed that changes in the gene dosage of certain regions due to CNVs proportionally affect the RNA expression levels of those corresponding regions ${ }^{[6]]}$.

Although few studies have reported on the heterogeneity of liver CSCs at the single-cell level in HCC, a recent study showed that different CSC subpopulations contain distinct molecular signatures, suggesting that CSC heterogeneity may contribute to the molecular and biological diversity of HCC cell groups and, consequently, patient prognosis ${ }^{[67]}$. Therefore, heterogeneity at the single cell level of liver CSCs may be critical for tumor progression and prognosis in HCC and might be important for the development of targeted agents for HCC. 
It is generally accepted that tumor development and progression are closely linked to the failure of immune surveillance, which includes elimination of tumor cells at the initial stage or immune defense to prevent immune escape ${ }^{[68]}$. In general, activated CD8+ T cells are essential in anti-cancer immunity, while regulatory $\mathrm{T}$ cells (Tregs) mediate significant immune dysfunction against cancer ${ }^{[69]}$. The main reason for the decline of anti-cancer immunity is T cell dysfunction or exhaustion. Several factors responsible for this phenomenon have been proposed, including abnormal increases in check point inhibitors, such as programmed cell death protein 1 (PD1), cytotoxic T lymphocyte antigen 4 (CTLA4), lymphocyte activation gene 3 protein (LAG3), and killer cell lectin-like receptor G1 (KLRG1) ${ }^{[70]}$. Moreover, tumor-infiltrating lymphocytes (TILs) surrounding cancer play an important role in host immunosurveillance associated with tumor biology. TILs present in HCC are composed of intratumoral CD8 $+\mathrm{T}$ cells and peritumoral CD4+ T cells independent of histogenetic origin ${ }^{[71]}$ but their roles in tumor killing are not clearly understood. More recently, Zheng et al. ${ }^{[72]}$ carried out deep scRNA-seq on 5063 single T cells isolated from peripheral blood, tumor, and surrounding non-tumoral tissue from 6 HCC patients. Analyzing the transcriptional profiles of these individual cells coupled with assembled $\mathrm{T}$ cell receptor (TCR) sequences, 11 functional $\mathrm{T}$ cell subsets were identified based on their molecular and functional properties. Specific subsets, such as exhausted CD $8+\mathrm{T}$ cells and Tregs, are preferentially enriched and potentially clonally expanded in HCC. FOXP3, CTLA4, TNFRSF18, TNFRSF4 and CCR8 were highly expressed in tumor-infiltrating Tregs, while MYO7A, WARS, andCXCL13 LAYN, PHLDA1, and SNAP47 were identified in tumor-infiltrating exhausted CD8+ T cells. In particular, high expression of PHLDA1 and SNAP47 was significantly associated with poor prognosis in HCC patients. In addition, it was demonstrated that LYAN was highly expressed in both tumor Tregs and exhausted CD $8+\mathrm{T}$ cells from tumor tissue of HCC and shown that LYAN is up-regulated on activated CD8+ T cells and Tregs, repressing the $\mathrm{CD} 8+\mathrm{T}$ cell function in vitro ${ }^{[72]}$. These data are crucial for understanding hepatocarcinogenesis and developing targeted immunotherapies in HCC.

\section{CONCLUSION}

The pathogenesis of HCC is very complicated and depends on the specific etiologic factors involved. HCC pathogenesis is a multistep process that involves diverse molecular and cellular signaling pathways. For this reason, patients with HCC should be managed with multiple therapeutic modalities by multidisciplinary teams rather than a single treatment approach to achieve better clinical outcomes. The major risk factors for HCC include hepatitis B and C virus infection, alcohol, NAFLD, chemical toxins and hereditary disorders. During hepatocarcinogenesis, numerous factors, such as oxidative stress, inflammation, hormone systems, hypoxia and immunity, are dysregulated, leading to the development of HCC. Nonetheless, the precise molecular mechanisms defining the development of HCC have not been entirely elucidated. Emerging scRNAseq technology is a powerful tool for defining sub-populations of cells within a heterogeneous bulk of tumor tissue and has been a breakthrough that has the potential to unveil the molecular mechanisms of HCC. In addition, single-cell genome analysis can be applied to monitor circulating tumor cells and cell-free DNA to evaluate tumor recurrence. Moreover, analysis of the transcriptome heterogeneity and characterization of the heterogeneous molecular signatures in HCC will lead to development of novel therapeutic target agents and ultimately help tailor individual cancer therapy.

\section{DECLARATIONS}

\section{Authors' contributions}

The author contributed solely to the paper.

\section{Availability of data and materials}

Not applicable.

\section{Financial support and sponsorship}

This research was supported by grants of Global High-tech Biomedicine Technology Development Program 
of the National Research Foundation (NRF) \& Korea Health Industry Development Institute (KHIDI) funded by the Korean government (MSIP\&MOHW) (No. 2015M3D6A1065146).

\section{Conflicts of interest}

The author declared that there are no conflicts of interest.

\section{Ethical approval and consent to participate}

Not applicable.

\section{Consent for publication}

Not applicable.

\section{Copyright}

(c) The Author(s) 2018.

\section{REFERENCES}

1. Yang JD, Roberts LR. Epidemiology and management of hepatocellular carcinoma. Infect Dis Clin North Am 2010;24:899-919, viii.

2. Venook AP, Papandreou C, Furuse J, de Guevara LL. The incidence and epidemiology of hepatocellular carcinoma: a global and regional perspective. Oncologist 2010;15 Suppl 4:5-13.

3. Sanyal AJ, Yoon SK, Lencioni R. The etiology of hepatocellular carcinoma and consequences for treatment. Oncologist 2010;15 Suppl 4:14-22.

4. Welzel TM, Graubard BI, Zeuzem S, El-Serag HB, Davila JA, McGlynn KA. Metabolic syndrome increases the risk of primary liver cancer in the United States: a study in the SEER-Medicare database. Hepatology 2011;54:463-71.

5. Liu Y, Chang CC, Marsh GM, Wu F. Population attributable risk of aflatoxin-related liver cancer: systematic review and meta-analysis. Eur J Cancer 2012;48:2125-36.

6. Ferber MJ, Montoya DP, Yu C, Aderca I, McGee A, Thorland EC, Nagorney DM, Gostout BS, Burgart LJ, Boix L, Bruix J, McMahon BJ, Cheung TH, Chung TK, Wong YF, Smith DI, Roberts LR. Integrations of the hepatitis B virus (HBV) and human papillomavirus (HPV) into the human telomerase reverse transcriptase (hTERT) gene in liver and cervical cancers. Oncogene 2003;22:3813-20.

7. Zhang X, Ding HG. Key role of hepatitis B virus mutation in chronic hepatitis B development to hepatocellular carcinoma. World J Hepatol 2015;7:1282-6.

8. Sung WK, Zheng H, Li S, Chen R, Liu X, Li Y, Lee NP, Lee WH, Ariyaratne PN, Tennakoon C, Mulawadi FH, Wong KF, Liu AM, Poon RT, Fan ST, Chan KL, Gong Z, Hu Y, Lin Z, Wang G, Zhang Q, Barber TD, Chou WC, Aggarwal A, Hao K, Zhou W, Zhang C, Hardwick J, Buser C, Xu J, Kan Z, Dai H, Mao M, Reinhard C, Wang J, Luk JM. Genome-wide survey of recurrent HBV integration in hepatocellular carcinoma. Nat Genet 2012;44:765-9.

9. Nault JC, Mallet M, Pilati C, Calderaro J, Bioulac-Sage P, Laurent C, Laurent A, Cherqui D, Balabaud C, Zucman-Rossi J. High frequency of telomerase reverse-transcriptase promoter somatic mutations in hepatocellular carcinoma and preneoplastic lesions. Nat Commun 2013;4:2218.

10. Bell RJ, Rube HT, Kreig A, Mancini A, Fouse SD, Nagarajan RP, Choi S, Hong C, He D, Pekmezci M, Wiencke JK, Wrensch MR, Chang SM, Walsh KM, Myong S, Song JS, Costello JF. Cancer. The transcription factor GABP selectively binds and activates the mutant TERT promoter in cancer. Science 2015;348:1036-9.

11. Zhang T, Zhang J, You X, Liu Q, Du Y, Gao Y, Shan C, Kong G, Wang Y, Yang X, Ye L, Zhang X. Hepatitis B virus X protein modulates oncogene Yes-associated protein by CREB to promote growth of hepatoma cells. Hepatology 2012;56:2051-9.

12. Maguire HF, Hoeffler JP, Siddiqui A. HBV X protein alters the DNA binding specificity of CREB and ATF-2 by protein-protein interactions. Science 1991;252:842-4.

13. Chan C, Wang Y, Chow PK, Chung AY, Ooi LL, Lee CG. Altered binding site selection of $\mathrm{p} 53$ transcription cassettes by hepatitis B virus X protein. Mol Cell Biol 2013;33:485-97.

14. Yun C, Um HR, Jin YH, Wang JH, Lee MO, Park S, Lee JH, Cho H. NF-kappaB activation by hepatitis B virus X (HBx) protein shifts the cellular fate toward survival. Cancer Lett 2002;184:97-104.

15. Klein NP, Schneider RJ. Activation of Src family kinases by hepatitis B virus HBx protein and coupled signaling to Ras. Mol Cell Biol 1997;17:6427-36.

16. Benn J, Schneider RJ. Hepatitis B virus HBx protein activates Ras-GTP complex formation and establishes a Ras, Raf, MAP kinase signaling cascade. Proc Natl Acad Sci U S A 1994;91:10350-4.

17. Lee YI, Kang-Park S, Do SI, Lee YI. The hepatitis B virus-X protein activates a phosphatidylinositol 3-kinase-dependent survival signaling cascade. J Biol Chem 2001;276:16969-77.

18. Cha MY, Kim CM, Park YM, Ryu WS. Hepatitis B virus X protein is essential for the activation of Wnt/beta-catenin signaling in hepatoma cells. Hepatology 2004;39:1683-93.

19. Tian Y, Yang W, Song J, Wu Y, Ni B. Hepatitis B virus X protein-induced aberrant epigenetic modifications contributing to human hepatocellular carcinoma pathogenesis. Mol Cell Biol 2013;33:2810-6.

20. Zhu YZ, Zhu R, Fan J, Pan Q, Li H, Chen Q, Zhu HG. Hepatitis B virus X protein induces hypermethylation of p16(INK4A) promoter via 
DNA methyltransferases in the early stage of HBV-associated hepatocarcinogenesis. J Viral Hepat 2010;17:98-107.

21. Kong G, Zhang J, Zhang S, Shan C, Ye L, Zhang X. Upregulated microRNA-29a by hepatitis B virus X protein enhances hepatoma cell migration by targeting PTEN in cell culture model. PLoS One 2011;6:e19518.

22. Rusyn I, Lemon SM. Mechanisms of HCV-induced liver cancer: what did we learn from in vitro and animal studies? Cancer Lett 2014;345:210-5.

23. Lerat H, Higgs M, Pawlotsky JM. Animal models in the study of hepatitis C virus-associated liver pathologies. Expert Rev Gastroenterol Hepatol 2011;5:341-52.

24. Lindenbach BD, Evans MJ, Syder AJ, Wolk B, Tellinghuisen TL, Liu CC, Maruyama T, Hynes RO, Burton DR, McKeating JA, Rice CM. Complete replication of hepatitis C virus in cell culture. Science 2005;309:623-6.

25. Lohmann V, Korner F, Koch J, Herian U, Theilmann L, Bartenschlager R. Replication of subgenomic hepatitis C virus RNAs in a hepatoma cell line. Science 1999;285:110-3.

26. Tacke RS, Tosello-Trampont A, Nguyen V, Mullins DW, Hahn YS. Extracellular hepatitis C virus core protein activates STAT3 in human monocytes/macrophages/dendritic cells via an IL-6 autocrine pathway. J Biol Chem 2011;286:10847-55.

27. Zhu Z, Wilson AT, Gopalakrishna K, Brown KE, Luxon BA, Schmidt WN. Hepatitis C virus core protein enhances Telomerase activity in Huh7 cells. J Med Virol 2010;82:239-48.

28. He Q, Cheng R, Chen Z, Xiao X, Xiao Z, Li C, Li B, Zhang P, Zheng H, Feng D. Cell transformation and proteome alteration in QSG7701 cells transfected with hepatitis C virus non-structural protein 3. Acta Biochim Biophys Sin (Shanghai) 2007;39:751-62.

29. Kwun HJ, Jung EY, Ahn JY, Lee MN, Jang KL. p53-dependent transcriptional repression of p21(waf1) by hepatitis C virus NS3. J Gen Virol 2001;82:2235-41.

30. Yu GY, He G, Li CY, Tang M, Grivennikov S, Tsai WT, Wu MS, Hsu CW, Tsai Y, Wang LH, Karin M. Hepatic expression of HCV RNAdependent RNA polymerase triggers innate immune signaling and cytokine production. Mol Cell 2012;48:313-21.

31. Korenaga M, Wang T, Li Y, Showalter LA, Chan T, Sun J, Weinman SA. Hepatitis C virus core protein inhibits mitochondrial electron transport and increases reactive oxygen species (ROS) production. J Biol Chem 2005;280:37481-8.

32. Munakata T, Nakamura M, Liang Y, Li K, Lemon SM. Down-regulation of the retinoblastoma tumor suppressor by the hepatitis C virus NS5B RNA-dependent RNA polymerase. Proc Natl Acad Sci U S A 2005;102:18159-64.

33. Choi SH, Hwang SB. Modulation of the transforming growth factor-beta signal transduction pathway by hepatitis $\mathrm{C}$ virus nonstructural $5 \mathrm{~A}$ protein. J Biol Chem 2006;281:7468-78.

34. Tsai WC, Hsu SD, Hsu CS, Lai TC, Chen SJ, Shen R, Huang Y, Chen HC, Lee CH, Tsai TF, Hsu MT, Wu JC, Huang HD, Shiao MS, Hsiao M, Tsou AP. MicroRNA-122 plays a critical role in liver homeostasis and hepatocarcinogenesis. J Clin Invest 2012;122:2884-97.

35. Smeenk R, Duin T, Aarden L. Influence of $\mathrm{pH}$ on the detection of low- and high-avidity anti-dsDNA. J Immunol Methods 1982;55:361-73.

36. Abbas Z, Abbas M, Abbas S, Shazi L. Hepatitis D and hepatocellular carcinoma. World J Hepatol 2015;7:777-86.

37. Schwartz JM, Reinus JF. Prevalence and natural history of alcoholic liver disease. Clin Liver Dis 2012;16:659-66.

38. Neuman MG, Malnick S, Maor Y, Nanau RM, Melzer E, Ferenci P, Seitz HK, Mueller S, Mell H, Samuel D, Cohen LB, Kharbanda KK, Osna NA, Ganesan M, Thompson KJ, McKillop IH, Bautista A, Bataller R, French SW. Alcoholic liver disease: clinical and translational research. Exp Mol Pathol 2015;99:596-610.

39. Plemenitas A, Kastelic M, Porcelli S, Serretti A, Rus Makovec M, Kores Plesnicar B, Dolzan V. Genetic variability in CYP2E1 and catalase gene among currently and formerly alcohol-dependent male subjects. Alcohol Alcohol 2015;50:140-5.

40. Polonikov AV, Ivanov VP, Solodilova MA. CYP2E1 gene promoter polymorphism -1293G $>$ C increases the risk of essential hypertension in men with alcohol abuse. Bull Exp Biol Med 2013;155:734-7.

41. Liu W, Tian F, Dai L, Chai Y. Cytochrome P450 2E1 gene polymorphism and alcohol drinking on the risk of hepatocellular carcinoma: a meta-analysis. Mol Biol Rep 2014;41:7645-50.

42. Schulze K, Imbeaud S, Letouze E, Alexandrov LB, Calderaro J, Rebouissou S, Couchy G, Meiller C, Shinde J, Soysouvanh F, Calatayud AL, Pinyol R, Pelletier L, Balabaud C, Laurent A, Blanc JF, Mazzaferro V, Calvo F, Villanueva A, Nault JC, Bioulac-Sage P, Stratton MR, Llovet JM, Zucman-Rossi J. Exome sequencing of hepatocellular carcinomas identifies new mutational signatures and potential therapeutic targets. Nat Genet 2015;47:505-11.

43. Sebastian C, Satterstrom FK, Haigis MC, Mostoslavsky R. From sirtuin biology to human diseases: an update. J Biol Chem 2012;287:42444-52

44. You M, Liang X, Ajmo JM, Ness GC. Involvement of mammalian sirtuin 1 in the action of ethanol in the liver. Am J Physiol Gastrointest Liver Physiol 2008;294:G892-8.

45. Stunkel W, Peh BK, Tan YC, Nayagam VM, Wang X, Salto-Tellez M, Ni B, Entzeroth M, Wood J. Function of the SIRT1 protein deacetylase in cancer. Biotechnol J 2007;2:1360-8.

46. Luo J, Nikolaev AY, Imai S, Chen D, Su F, Shiloh A, Guarente L, Gu W. Negative control of p53 by Sir2alpha promotes cell survival under stress. Cell 2001;107:137-48

47. Yeung F, Hoberg JE, Ramsey CS, Keller MD, Jones DR, Frye RA, Mayo MW. Modulation of NF-kappaB-dependent transcription and cell survival by the SIRT1 deacetylase. EMBO J 2004;23:2369-80.

48. Jang KY, Noh SJ, Lehwald N, Tao GZ, Bellovin DI, Park HS, Moon WS, Felsher DW, Sylvester KG. SIRT1 and c-Myc promote liver tumor cell survival and predict poor survival of human hepatocellular carcinomas. PLoS One 2012;7:e45119.

49. Mercer KE, Hennings L, Ronis MJ. Alcohol consumption, Wnt/beta-catenin signaling, and hepatocarcinogenesis. Adv Exp Med Biol 2015;815:185-95.

50. Lindenmeyer CC, McCullough AJ. The natural history of nonalcoholic fatty liver disease-an evolving view. Clin Liver Dis 2018;22:11-21.

51. Agosti P, Sabba C, Mazzocca A. Emerging metabolic risk factors in hepatocellular carcinoma and their influence on the liver microenvironment. Biochim Biophys Acta 2018;1864:607-17.

52. Wong RJ, Aguilar M, Cheung R, Perumpail RB, Harrison SA, Younossi ZM, Ahmed A. Nonalcoholic steatohepatitis is the second leading etiology of liver disease among adults awaiting liver transplantation in the United States. Gastroenterology 2015;148:547-55. 
53. Wu J. Utilization of animal models to investigate nonalcoholic steatohepatitis-associated hepatocellular carcinoma. Oncotarget 2016;7:42762-76.

54. Ding J, Wu J. Epigenetic regulation of hepatic tumor-initiating cells. Front Biosci (Landmark Ed) 2015;20:946-63.

55. Stickel F, Hellerbrand C. Non-alcoholic fatty liver disease as a risk factor for hepatocellular carcinoma: mechanisms and implications. Gut 2010;59:1303-7.

56. Park EJ, Lee JH, Yu GY, He G, Ali SR, Holzer RG, Osterreicher CH, Takahashi H, Karin M. Dietary and genetic obesity promote liver inflammation and tumorigenesis by enhancing IL-6 and TNF expression. Cell 2010;140:197-208.

57. Yoshimoto S, Loo TM, Atarashi K, Kanda H, Sato S, Oyadomari S, Iwakura Y, Oshima K, Morita H, Hattori M, Honda K, Ishikawa Y, Hara E, Ohtani N. Obesity-induced gut microbial metabolite promotes liver cancer through senescence secretome. Nature 2013;499:97-101.

58. Streba LA, Vere CC, Rogoveanu I, Streba CT. Nonalcoholic fatty liver disease, metabolic risk factors, and hepatocellular carcinoma: an open question. World J Gastroenterol 2015;21:4103-10.

59. Hardy T, Oakley F, Anstee QM, Day CP. Nonalcoholic fatty liver disease: pathogenesis and disease spectrum. Annu Rev Pathol 2016;11:451-96.

60. Wang Z, Gerstein M, Snyder M. RNA-Seq: a revolutionary tool for transcriptomics. Nat Rev Genet 2009;10:57-63.

61. Miyamoto DT, Zheng Y, Wittner BS, Lee RJ, Zhu H, Broderick KT, Desai R, Fox DB, Brannigan BW, Trautwein J, Arora KS, Desai N, Dahl DM, Sequist LV, Smith MR, Kapur R, Wu CL, Shioda T, Ramaswamy S, Ting DT, Toner M, Maheswaran S, Haber DA. RNA-Seq of single prostate CTCs implicates noncanonical Wnt signaling in antiandrogen resistance. Science 2015;349:1351-6.

62. Xu S, Lou F, Wu Y, Sun DQ, Zhang JB, Chen W, Ye H, Liu JH, Wei S, Zhao MY, Wu WJ, Su XX, Shi R, Jones L, Huang XF, Chen SY, Chen J. Circulating tumor DNA identified by targeted sequencing in advanced-stage non-small cell lung cancer patients. Cancer Lett 2016;370:324-31.

63. Liang DH, Ensor JE, Liu ZB, Patel A, Patel TA, Chang JC, Rodriguez AA. Cell-free DNA as a molecular tool for monitoring disease progression and response to therapy in breast cancer patients. Breast Cancer Res Treat 2016;155:139-49.

64. Huang Q, Lin B, Liu H, Ma X, Mo F, Yu W, Li L, Li H, Tian T, Wu D, Shen F, Xing J, Chen ZN. RNA-Seq analyses generate comprehensive transcriptomic landscape and reveal complex transcript patterns in hepatocellular carcinoma. PLoS One 2011;6:e26168.

65. Marusyk A, Almendro V, Polyak K. Intra-tumour heterogeneity: a looking glass for cancer? Nat Rev Cancer 2012;12:323-34.

66. Hou Y, Guo H, Cao C, Li X, Hu B, Zhu P, Wu X, Wen L, Tang F, Huang Y, Peng J. Single-cell triple omics sequencing reveals genetic, epigenetic, and transcriptomic heterogeneity in hepatocellular carcinomas. Cell Res 2016;26:304-19.

67. Zheng H, Pomyen Y, Hernandez MO, Li C, Livak F, Tang W, Dang H, Greten TF, Davis JL, Zhao Y, Mehta M, Levin Y, Shetty J, Tran B, Budhu A, Wang XW. Single cell analysis reveals cancer stem cell heterogeneity in hepatocellular carcinoma. Hepatology 2018;68:127-40.

68. Hurez V, Padron A, Svatek RS, Curiel TJ. Considerations for successful cancer immunotherapy in aged hosts. Exp Gerontol 2018;107:2736.

69. Curiel TJ. Regulatory T cells and treatment of cancer. Curr Opin Immunol 2008;20:241-6.

70. Wherry EJ. T cell exhaustion. Nat Immunol 2011;12:492-9.

71. Kasper HU, Drebber U, Stippel DL, Dienes HP, Gillessen A. Liver tumor infiltrating lymphocytes: comparison of hepatocellular and cholangiolar carcinoma. World J Gastroenterol 2009;15:5053-7.

72. Zheng C, Zheng L, Yoo JK, Guo H, Zhang Y, Guo X, Kang B, Hu R, Huang JY, Zhang Q, Liu Z, Dong M, Hu X, Ouyang W, Peng J, Zhang Z. Landscape of infiltrating T cells in liver cancer revealed by single-cell sequencing. Cell 2017;169:1342-56.e16. 